\title{
Can kunzea oil (Kunzea ambigua) control head lice (Pediculus humanus capitis)?
}

\author{
C. R. WILLIAMS ${ }^{1}$, C. E. WEBB ${ }^{2}$, S. ORRE ${ }^{1}$, M. NAUNTON ${ }^{3}$ and J. THOMAS ${ }^{3}$ * \\ ${ }^{1}$ Sansom Institute for Health Research, University of South Australia, Adelaide, SA 5001, Australia \\ ${ }^{2}$ Department of Medical Entomology, University of Sydney and Pathology West-ICPMR Westmead, Westmead \\ Hospital, NSW 2145, Australia \\ ${ }^{3}$ Faculty of Health, University of Canberra, Bruce, Canberra ACT 2601, Australia
}

(Received 8 Fune 2015; revised 28 Fuly 2015; accepted 6 August 2015)

\begin{abstract}
SUMMARY
Head lice (Pediculus humanus capitis) infestations are a public health concern. The insecticidal properties of the Australian native plant Kunzea ambigua (commonly known as tick bush) have been documented. In this study, we tested activity of kunzea oil (KO) against head lice through in vitro bioassays. Head lice were exposed to filter paper treated with either KO, as either a 5 or $100 \%$ oil, or commercial formulations containing either permethrin or tea tree oil (TTO) for $120 \mathrm{~min}$. Head lice exposure to $\mathrm{KO}$, both as a 5 and $100 \%$ solution oil, resulted in $100 \%$ mortality within 120 min with a mean survival times of 17.1 and $34.8 \mathrm{~min}$, respectively. There was no significant difference between the mean mortality of head lice exposed to $5 \% \mathrm{KO}(17 \cdot 1 \pm 1 \cdot 0 ; 95 \% \mathrm{CI}: 115 \cdot 2-19 \cdot 0)$ and $5 \%$ TTO $(21 \cdot 2 \pm 1 \cdot 9 ; 95 \% \mathrm{CI}: 17 \cdot 4-25 \cdot 1)$. This study revealed, for the first time, that $\mathrm{KO}$ holds great potential as an effective alternative to current active ingredients contained within commercial pediculicide formulations.
\end{abstract}

Key words: Kunzea oil, Pediculus humanus capitis, Kunzea ambigua, tea tree oil, head lice, pediculicide, resistance.

\section{INTRODUCTION}

Pediculosis (infestation with head lice) has been reported as a chronic public health problem worldwide, particularly in children aged 3-13 (Speare and Buettner, 1999; Diamantis et al. 2009; Currie et al. 2010). Therapeutic management of pediculosis is challenging with increasing worldwide prevalence due to product failures resulting from resistance, incorrect application, formulation changes and misdiagnosis (Toloza et al. 2008). With a limited number of effective pediculicides available, plantderived compounds hold great potential due to demonstrated repellent, ovicidal, adulticidal and feeding inhibition activity against various arthropods including head lice (Audino et al. 2007).

Like tea tree oil (TTO), kunzea oil (KO) is a myrtaceous essential oil; although it differs in composition to TTO, comprising about $70 \%$ monoterpenes but with characteristic sesquiterpenes (Thomas et al. 2010). Kunzea spp. plant extracts have insecticidal properties (Khambay et al. 1999, 2002). KO was shown to be repellent to host-seeking mosquitoes in the laboratory testing with comparable efficacy to citronella (Thomas et al. 2009a, b). Given the demonstrated repellent activity against mosquitoes, it has been suggested that similar effectiveness may be achieved against other haematophagous

* Corresponding author. Faculty of Health, University of Canberra, Building 12 Level D Room 36, Kirinari Street, Bruce, Canberra, ACT 2601, Australia. E-mail: Jackson. Thomas@canberra.edu.au arthropods. The aim of this study was to investigate the ability of commercially available $\mathrm{KO}$ for its pediculicidal properties.

\section{EXPERIMENTAL METHODS}

\section{Collection of head lice for laboratory studies}

This work was approved by the University of South Australia's Human Research Ethics Committee (approvals 30059 and 32538). Head lice were obtained directly from the children (following written parental consent) at two primary schools in South Australia as well as a purpose run head lice clinic at the University of South Australia. Head lice were removed from individuals by combing dry hair from scalp to tip using a head lice comb (Barker and Altman, 2010). Head lice were removed and placed into a Petridish for holding (maximum $15 \mathrm{~min}$ ) until the testing could commence.

\section{Pediculicidal assay}

Each test Petridish contained a filter paper $(7 \mathrm{~cm}$ diameter) that was uniformly covered in $1 \mathrm{~mL}$ treatment or control products. These amounts were premeasured before trials and then applied immediately prior to testing against lice. KO (Therapeutic Goods Administration ARTG entry 72143; Ducane Estate, Waterhouse, Tasmania), both a 100 and $5 \%$ solution [in ethanol $(90 \%$ of $70 \% \mathrm{v} / \mathrm{v}$ ethanol and $5 \%$ glycerol)], was tested along with two commercially

Parasitology Open (2016), Vol. 2, e3; page 1 of 5. (C) Cambridge University Press 2016. This is an Open Access article, distributed under the terms of the Creative Commons Attribution licence (http://creativecommons.org/licenses/by/4.0/), which permits unrestricted re-use, distribution, and reproduction in any medium, provided the original work is properly cited. 
$30 \mathrm{~min}$

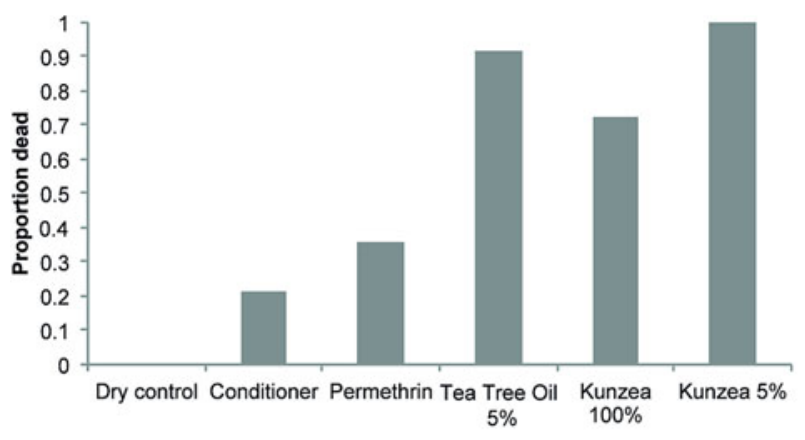

$90 \mathrm{~min}$

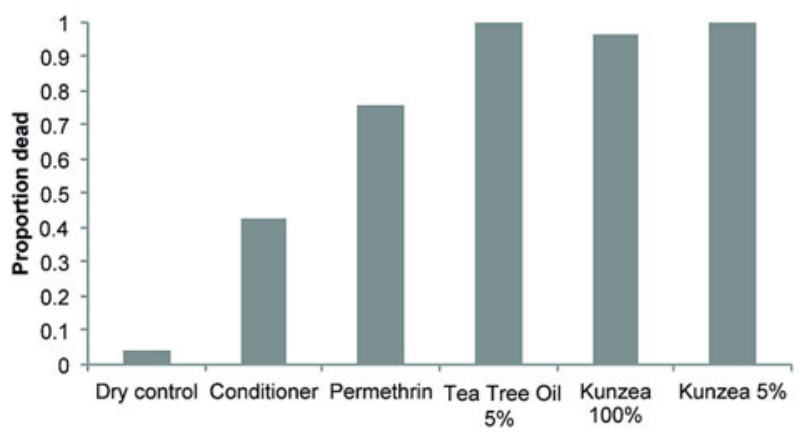

$60 \mathrm{~min}$

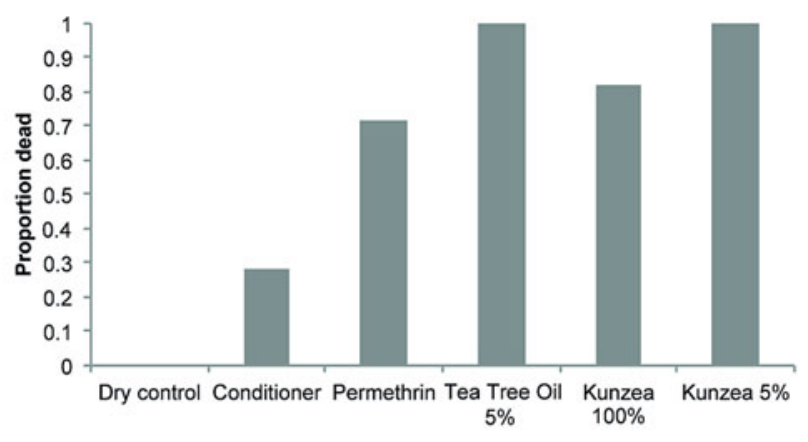

$120 \mathrm{~min}$

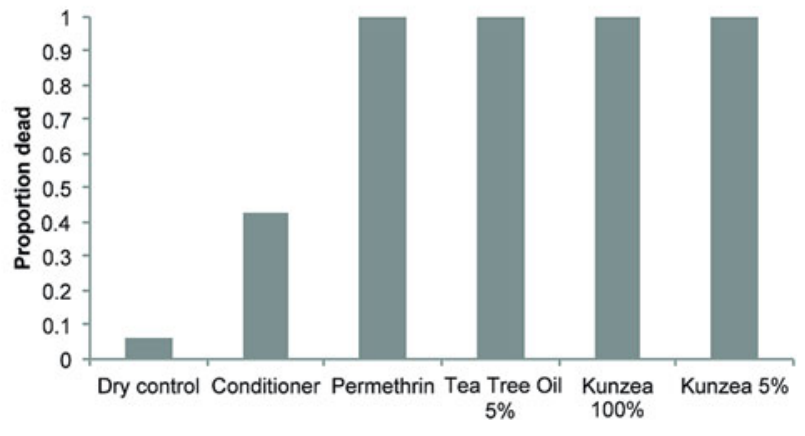

Fig. 1. Pediculicidal properties of kunzea oil preparations compared with positive and negative controls.

available formulations, TTO head lice gel (Integria Healthcare Australia Pty Ltd, Eight Mile Plains, QLD; containing 5\% TTO) and permethrin spray (Garrards Pesticides, Clovelly Park SA; containing $500 \mathrm{~g} \mathrm{~kg}^{-1}$ permethrin). The permethrin was included here as a positive control insecticide. Dimethicone-free hair conditioner (Moogoo Skin Care Pty Ltd, Brisbane, QLD) was tested as a wet control that may possess a suffocant effect against lice but no toxicosis.

Each formulation was applied evenly onto the filter paper contained within a Petridish and allowed it to dry for approximately $1 \mathrm{~h}$ prior to testing. As only head lice removed from a volunteer within 15 min were used, for each replicate test, 5-10 head lice were used. Head lice were transferred to a dish using a small, soft, bristled paintbrush and placed within the centre of the treated filter paper. Head lice were observed every $15 \mathrm{~min}$ for up to $120 \mathrm{~min}$ and the number of dead individual lice recorded at each time point. The number of replicate tests for each formulation and control varied between 3 and 9. Moribund lice responsive to touch with a probe were considered alive, while death was determined to have occurred when there was no response to the probe. Lice classified as dead never recovered. Mortality of head lice was recorded as the mean number of dead head lice across the replicate tests. Kaplan-Meier survival analysis (STATA version 12, College Station, USA) was used to compare pediculicidal effects of different treatments and to calculate mean survival times.

\section{RESULTS}

Exposure to $\mathrm{KO}$, both as a $5 \%$ and neat oil $(100 \%$, undiluted) resulted in $100 \%$ mortality within 120 min (Fig. 1) with the mean survival times of $17 \cdot 1$ min (5\% solution) and $34.8 \mathrm{~min}$ (neat oil; $100 \%$, undiluted) (Table 1). The mean survival time for the $5 \% \mathrm{KO}$ was the shortest of any other formulation tested and has now been shown to be extremely effective at killing lice in vitro and demonstrated the similar effectiveness to TTO (Fig. 1; Table 1). Kaplan-Meier survival analysis showed no significant difference in the mortality rate of $\mathrm{KO}$ compared with the TTO-based formulation (log-rank test, $P>$ $0 \cdot 05)$, which is also reflected in the mean survival times of lice exposed to the two oils (Table 1). Interestingly, the mean survival times of the permethrin-based formulation were substantially longer than both the KO and TTO-based formulations (Table 1). Over $40 \%$ mortality was recorded in head lice exposed to the plain hair conditioner after $90 \mathrm{~min}$, a significantly lower rate (log-rank test, $P<0.001)$ than any of the botanical or insecticide-based products. Less than $10 \%$ mortality was recorded in head lice in the dry control (nothing added to the filter paper) category after $120 \mathrm{~min}$ (Fig. 1). These differences in the mortality between $\mathrm{KO} / \mathrm{TTO}$ and the dry and wet controls were 
Table 1. Mean individual louse survival times and $95 \%$ confidence intervals (CI) when exposed to in vitro pediculicidal treatments, in descending order of pediculicidal activity

\begin{tabular}{llrr}
\hline \hline & Replicates & Mean survival time (min) & S.E. \\
\hline Kunzea oil (5\%) & 6 & $17 \cdot 1$ & $1 \cdot 0$ \\
$5 \%$ tea tree oil & 4 & $21 \cdot 2$ & $1 \cdot 9$ \\
Kunzea oil $(100 \%)$ & 9 & $34 \cdot 8$ & $3 \cdot 5$ \\
Permethrin & 4 & $56 \cdot 4$ & $7 \cdot 9-19 \cdot 0$ \\
Conditioner & 3 & $157 \cdot 5$ & $27 \cdot 8-41 \cdot 7$ \\
Dry control & 7 & $231 \cdot 3$ & $41 \cdot 0-71 \cdot 8$ \\
\hline \hline
\end{tabular}

statistically significant (log-rank test, $P<0 \cdot 001$ ). Survival analysis also revealed no significant differences in the mortality between $\mathrm{KO}$ and TTO.

\section{ISCUSSION}

This in vitro study demonstrates that the mean mortality of head lice exposed to KO does not differ appreciably to those exposed to currently registered formulations containing TTO. With the perception that formulations containing synthetic insecticides such as permethrin (Durand et al. 2012) may be driving the development of insecticide resistance, there is growing interest in novel pediculicides, particularly those of botanical origin, and a partial summary of the key candidates is summarized in Table 2. Botanical extracts avoid the problems arising from residual effects seen with synthetic pediculicides (Webb and Russell, 2011) and are very unlikely to yield resistance in lice because of multiple modes of action of each of their active principles (Carpinella et al. 2007). While commercial products containing botanical extracts are widely available and commonly used as both pediculicides and repellents against head lice, TTO-based formulations are most common. The results of this study demonstrate that $\mathrm{KO}$ as an active ingredient will provide comparable control of head lice to that of TTO.

Given the interest amongst the community for 'natural' solutions to head lice, it is important that appropriate testing be conducted to confirm the efficacy of any new pediculicide formulations (Heukelbach et al. 2008). Based on the results of this study, there is great potential in $\mathrm{KO}$ and that it has already demonstrated efficacy above the $80 \%$ mortality threshold suggested (Heukelbach et al. 2008). However, while in vitro testing shows great potential, it will be critical that controlled field trials and therapeutic potential of formulated products be assessed (Burkhart and Burkhart, 2001). The need for understanding the synergistic effect of non-active ingredients in commercial formulations was highlighted by the results of the testing presented here with 5\% $\mathrm{KO}$ recording a lower mean survival time compared with the neat oil $(100 \%$, undiluted).

Many local health authorities continue to preference the 'wet comb technique' as a head lice management strategy to reduce the possibility of overexposure to insecticides and minimizing the risk of insecticide resistance (Maxwell et al. 2014). However, the results of this study indicated that the use of conditioner does not provide the same level of pediculicidal action as that provided by KO. The dimethicone-free hair conditioner was tested but our data indicate that hair conditioner can kill only some adult lice, presumably through a suffocation effect. The use of hair conditioner without any active pediculicides present, physical suffocant properties of head lice will only assist in treatment if combined with a thorough combing and removal of 'stunned' head lice.

$\mathrm{KO}$ appears to be safe for topical application on the skin. $\mathrm{KO}$ has been tolerated well in clinical studies (human and animal) with concentrations ranging from 10 to $100 \%$ with no major documented solicited localized and/or systemic adverse drug reactions (Jacobson et al. 2009; Thomas et al. $2009 a, b, 2015)$. This includes application of oil and/or formulations at skin sites including open wounds (animal trial), inflamed skin (e.g. scalp psoriasis) and nails infected with fungal infection (both human trials). However, more work is required to further establish the optimum safe concentration of the oil for topical application. Repeated analyses of aged $\mathrm{KO}$ (6-36 months, stored at room temperature) did not show any noticeable change in the chemical profile of the oil indicating little degradation of oil resulting from oxidation and polymerization (J. Thomas, unpublished data). KO has been recently examined for its activity against ectoparasites (scabies mites and head lice) and did not show any appreciable activity against scabies mites below 5\% (J. Thomas, 2015, unpublished data). The 5\% TTO has demonstrated remarkable activity against human scabies mites (Walton et al. 2004), and the commercial 5\% TTO gel formulation has been widely used for the management of head lice in Australia. Therefore, a 5\% KO formulation has been used in our study for a direct comparison with the proprietary 5\% TTO head lice gel.

This study confirms the pediculicidal potential of $\mathrm{KO}$ and further investigation is required to determine formulations that can be used as effective alternatives to botanical or synthetic insecticides for the management of ectoparasitic infestations in 
Table 2. A partial summary of various essential oil with documented activity against Pediculus humanus capitis

\begin{tabular}{lll}
\hline \hline Essential oil & Species & Family \\
\hline Eucalyptus oil & Eucalyptus globules & Myrtacea \\
Marjoram oil & Origanum majorana & Lamiaceae \\
Pennyroyal oil & Mentha pulegium & Lamiaceae \\
Rosemary oil & Rosmarinus officinalis & Lamiaceae \\
Cade oil & Funiperus oxycedrus & Cupressaceae \\
Cardamone ceylon oil & Elettaria cardamomum & Zingiberaceae \\
Clove bud oil & Eugenia caryophyllata & Myrtaceae \\
Myrtle oil & Myrtus communis & Myrtaceae \\
Rosewood oil & Aniba rosaeodora & Lauraceae \\
Sage oil & Salvia officinalis & Lamiaceae \\
Tagetes oil & Tagetes minuta & Asteraceae \\
Cinnamon bark oil & Cinnamomum zeylanicum & Lauraceae \\
Neem oil & Azadirachta indica & Meliaceae \\
Clove oil & Syzygium aromaticum & Myrtaceae \\
Citronella oil & Cymbopogon winteratus & Poaceae \\
Lippia multiflora oil & Lippia multiflora Moldenke & Verbenaceae \\
Cardamom oil & Elettaria cardamomum & Zingiberaceae \\
Tea tree oil & Melaleuca alternifolia & Myrtaceae \\
\hline \hline
\end{tabular}

Adopted from Rossini et al. (2008) and Yang et al. (2004).

humans and animals. Despite active promotion of the head lice treatments, studies have found carers vary greatly in the treatments used against pediculosis (Maxwell et al. 2014). Recommendations for pediculicide use should be regularly reviewed in light of developing resistance levels and new therapies. The ideal head lice treatment has been defined as being safe, effective, easy to use, inexpensive and available without a prescription and as a single dose (Frankowski and Bocchini, 2010). Regardless of the development of novel pediculicide formulations, community education will remain a critical component of head lice management strategies.

\section{ACKNOWLEDGEMENTS}

Louise Massie provided great assistance at the Sansom Institute for Health Research Clinical Trials Facility. The cooperation of primary schools and their Principals was pivotal to this study and greatly appreciated.

\section{FINANCIAL SUPPORT}

This study was funded by the Faculty of Health, University of Canberra internal grant awarded to Dr Jackson Thomas.

\section{CONFLICT OF INTEREST}

The authors have no competing interests.

\section{ETHICAL STANDARDS}

The authors assert that all procedures contributing to this work comply with the ethical standards of the relevant national and institutional committees on human experimentation and with the Helsinki
Declaration of 1975 , as revised in 2008. This work was approved by the University of South Australia's Human Research Ethics Committee (approvals 30059 and 32538).

\section{REFERENCES}

Audino, P. G., Vassena, C., Zerba, E. and Picollo, M. (2007). Effectiveness of lotions based on essential oils from aromatic plants against permethrin resistant Pediculus humanus capitis. Archives of Dermatological Research 299, 389-392.

Barker, S. C. and Altman, P. M. (2010). A randomised, assessor blind, parallel group comparative efficacy trial of three products for the treatment of head lice in children-melaleuca oil and lavender oil, pyrethrins and piperonyl butoxide, and a "suffocation" product. BMC Dermatology 10,6 .

Burkhart, C. N. and Burkhart, C. G. (2001). Recommendation to standardize pediculicidal and ovicidal testing for head lice (Anoplura: Pediculidae). Fournal of Medical Entomology 38, 127-129.

Carpinella, M. C., Miranda, M., Almirón, W. R., Ferrayoli, C. G., Almeida, F. L. and Palacios, S. M. (2007). In vitro pediculicidal and ovicidal activity of an extract and oil from fruits of Melia azedarach L. Fournal of the American Academy of Dermatology 56, 250-256.

Currie, M. J., Reynolds, G. J., Glasgow, N. J. and Bowden, F. J. (2010). A pilot study of the use of oral ivermectin to treat head lice in primary school students in Australia. Pediatric Dermatology 27, 595-599.

Diamantis, S. A., Morrell, D. S. and Burkhart, C. N. (2009). Treatment of head lice. Dermatologic Therapy 22, 273-278.

Durand, R., Bouvresse, S., Berdjane, Z., Izri, A., Chosidow, O. and Clark, J. (2012). Insecticide resistance in head lice: clinical, parasitological and genetic aspects. Clinical Microbiology and Infection 18, 338-344.

Frankowski, B. L. and Bocchini, J. A. (2010). Head lice. Pediatrics 126, 392-403.

Heukelbach, J., Canyon, D., Oliveira, F., Muller, R. and Speare, R. (2008). In vitro efficacy of over-the-counter botanical pediculicides against the head louse Pediculus humanus var capitis based on a stringent standard for mortality assessment. Medical and Veterinary Entomology 22, 264-272.

Jacobson, G. A., Narkowicz, C., Thomas, J. and Peterson, G. M. (2009). Clinical Trial of Kunzea Oil for Onychomycosis Treatment: a Randomised Controlled Trial. Rural Industries Research \& Development Corporation, Publication No. 09/098, pp. 4-5.

Khambay, B. P., Beddie, D. G., Simmonds, M. S. and Green, P. W. (1999). A new insecticidal pyranocyclohexenedione from Kunzea ericifolia. Fournal of Natural Products 62, 1423-1424. 
Khambay, B. P., Beddie, D. G. and Simmonds, M. S. (2002). An insecticidal mixture of tetramethylcyclohexenedione isomers from Kunzea ambigua and Kunzea baxterii. Phytochemistry 59, 69-71.

Maxwell, M., Crawford, B. and Rose, V. (2014). Nitbusters: lessons from a school-based intervention study to reduce head lice in a disadvantaged community. Health Promotion Fournal of Australia 25, $67-68$

Rossini, C., Castillo, L. and González, A. (2008). Plant extracts and their components as potential control agents against human head lice. Phytochemistry Reviews 7, 51-63.

Speare, R. and Buettner, P. G. (1999). Head lice in pupils of a primary school in Australia and implications for control. International fournal of Dermatology 38, 285-290.

Thomas, J., Narkowicz, C., Peterson, G. M., Jacobson, G. A. and Narayana, A. (2009a). Treatment of pastern dermatitis with a formulation containing kunzea oil: a randomised controlled trial. Veterinary Record 20, 619-623.

Thomas, J., Webb, C., Narkowicz, C., Jacobson, G., Peterson, G., Davies, N. and Russell, R. (2009b). Evaluation of repellent properties of volatile extracts from the Australian native plant Kunzea ambigua against Aedes aegypti (Diptera: Culcidae). Fournal of Medical Entomology 46, 1387-1391.
Thomas, J., Narkowicz, C., Jacobson, G. and Davies, N. (2010). An examination of the essential oils of Tasmanian Kunzea ambigua, other Kunzea spp. and commercial kunzea oil. Fournal of Essential Oil Research 22, 381-385

Thomas, J., Jacobson, G. A., Narkowicz, C. and Peterson, G. M. (2015). Safety and efficacy of kunzea oil-containing formulations for the management of psoriasis: a randomized, controlled trial. Fournal of Clinical Pharmacy and Therapeutics 40, 566-572.

Toloza, A. C., Lucia, A., Zerba, E., Masuh, H. and Picollo, M. I. (2008). Interspecific hybridization of Eucalyptus as a potential tool to improve the bioactivity of essential oils against permethrin-resistant head lice from Argentina. Bioresource Technology 99, 7341-7347.

Walton, S. F., McKinnon, M., Pizzutto, S., Dougall, A., Williams, E. and Currie, B. J. (2004). Acaricidal activity of Melaleuca alternifolia (tea tree) oil: in vitro sensitivity of Sarcoptes scabiei var. hominis to terpinen4-ol. Archives of Dermatology 140, 563-566.

Webb, C. E. and Russell, R. C. (2011). Advice to travellers on topical insect repellent use against dengue mosquitoes in far north Queensland, Australia. Fournal of Travel Medicine 18, 282-283.

Yang, Y. C., Lee, H. S., Clark, J. M. and Ahn, Y. J. (2004). Insecticidal activity of plant essential oils against Pediculus humanus capitis (Anoplura: Pediculidae). Fournal of Medical Entomology 41, 699-704. 